\title{
Partner notification for HIV infection in Denmark: attitudes and preliminary results
}

\author{
Anne-Marie Worm, Else Smith, Hanne Sørensen, Henrik Haxholdt
}

Objectives: To examine attitudes, experience and preliminary results of partner notification (PN) for HIV infection in Denmark among the doctors who inform one of their patients about being HIV infected.

Method: The doctors who had reported to the national HIV surveillance unit about a new-identified HIV infected person, during a 9 months period, were searched for one year later. The traced doctors were interviewed. The results of the interview related to 102 out of $195(52 \%)$ reports were compared between the 48 interviewed general practitioners (GPs) and the 33 interviewed hospital doctors (HDs). The proportion of traced reporting doctors were higher among GPs than among HDs.

Results: Both GPs and HDs found it difficult to give a positive HIV test result and wanted trained counsellors to work with them in the PN process: Less experience and fewer post-graduate courses about HIV may explain the GPs' lack of confidence to follow-up asymptomatic HIV positive patients. It was neither a routine for all the GPs or for all HDs to ask about patient behaviour nor to discuss safe sex with their index patients, and screening for other sexually transmitted diseases were seldomly performed. The numbers of partners notified, especially by the doctors were low.

Conclusions: HIV reporting doctors in Denmark are motivated for PN. Educational programmes about counselling and care of HIV infected patients should, however, be offered at intervals, especially to GPs. The outcome of PN can only be measured to a certain level as long as exposed partners are neither obliged to be tested nor to be counselled and as long as information about counselling and testing can not be shared between doctors in different settings.

(Genitourin Med 1996;72:283-285)

Keywords: HIV; partner notification; general practice

\section{Introduction}

Partner notification (PN) is one of the means of controlling treatable sexually transmitted diseases (STDs). ${ }^{1}$ The discussion of the role of $\mathrm{PN}$ in the control of HIV has been controversial, ${ }^{23}$ but during recent years has been reevaluated as a mean of intervention. ${ }^{48}$

In Denmark PN is recommended by the National Board of Health and it is in most cases a matter for the HIV diagnosing doctor, one third of whom are general practitioners without any formal training in PN. No baseline information about the attitudes to and results of the PN process exists.

\footnotetext{
Department of

Dermato-Venereology, Bispebjerg Hospital

A-M Worm

H Sørensen

Department of

Epidemiology, Statens

Seruminstitut

E Smith

General Practice

Nørrebrogade 220,

Copenhagen, Denmark

H Haxholdt

Address correspondence to: A-M Worm, Department of Dermato-Venereology, Bispebjerg Hospital, DK-2400 Copenhagen NV Denmark.

Accepted for publication 14 March 1996
}

\section{Material and methods}

The Danish mandatory HIV reporting system is based upon anonymous reports about persons for the first time diagnosed as HIV infected. A blank report is sent to the HIV testing doctor/clinic together with the positive HIV test result. The original report is returned to the national surveillance unit. Two copies are to be kept, one for the file of the patient and one for the doctor's own centralised filing system. During a nine month period (October 1992 to July 1993) the national surveillance unit received 195 reports. From October 1993 until July 1994, the reporting doctors were searched for and if traced then asked to participate in a structured face-to-face interview undertaken by a trained counsellor. The tracing procedure was complicated by insufficient information on the report and by the reporting doctors/clinics incomplete filing system. The study was approved by the National Ethical Committee.

\section{Results \\ Reports}

The reporting doctor's working place was in general practice $(31 \%)$, departments of infectious diseases $(24 \%)$, departments of dermato-venereology (17\%), other hospital departments or clinics $(21 \%)$, or unknown (7\%). The reporting doctor was traced and interviewed for $102(52 \%)$ reports, traced but declined an interview for 7 reports $(4 \%)$ and not traced for $86(44 \%)$ reports. Among the traced and "interviewed" reports 52/60 (87\%) were from general practice, $26 / 34(76 \%)$ from dermato-venereology, $9 / 47$ (19\%) from infectious medicine, and 15/41 (37\%) from other hospital departments or clinics.

\section{Index doctors}

The 102 reports came from 81 different index doctors, 48 general practitioners (GPs) and 33 doctors from hospitals and clinics (HDs). The median age was similar (46 years), but the male/female ratio was higher among GPs (3.8) than among HDs $(0.9)$, $(p<0.005)$. A selection of the information given is presented in table 1. The majority, of both GPs and HDs, said that: it is difficult to give a positive HIV test result (79\%); they would ask the patient directly 
Table 1 Information given by HIV reporting general practitioners (GPS) and hospital doctors (HDs) (percentages in brackets)

\begin{tabular}{|c|c|c|c|}
\hline & $G P s(n=48)$ & $H D s(n=33)$ & p value \\
\hline Ever HIV course & $35(73)$ & $28(85)$ & NS \\
\hline More HIV courses & $18(37)$ & $19(58)$ & NS \\
\hline \multicolumn{4}{|l|}{ HIV testing activity (monthly) } \\
\hline $\begin{array}{l}1-5 \text { test } \\
\geqslant 6\end{array}$ & $\begin{array}{l}29(60) \\
19(40)\end{array}$ & $\begin{array}{l}15(45) \\
18(55)\end{array}$ & NS \\
\hline \multicolumn{4}{|l|}{ HIV diagnoses last year } \\
\hline $\begin{array}{l}\leqslant 2 \\
\geqslant 3\end{array}$ & $\begin{array}{l}45(94) \\
3(6)\end{array}$ & $\begin{array}{l}19(58) \\
14(42)\end{array}$ & $\begin{array}{l}<0.0001 \\
<0.0001\end{array}$ \\
\hline \multicolumn{4}{|l|}{ HIV diagnoses ever } \\
\hline $\begin{array}{l}\leqslant 2 \\
\geqslant 3\end{array}$ & $\begin{array}{l}34(71) \\
14(29)\end{array}$ & $\begin{array}{r}8(24) \\
25(76)\end{array}$ & $\begin{array}{l}<0.0001 \\
<0.0001\end{array}$ \\
\hline Have sufficient knowledge to follow asymptomatic HIV patients & $28(58)$ & $28(85)$ & $<0.01$ \\
\hline $\begin{array}{l}\text { Known the patient } \leqslant \text { one month before HIV testing } \\
\text { No of patient visits before testing }\end{array}$ & $14(29)$ & $29(91)$ & $<0.000001$ \\
\hline $\begin{array}{l}\text { No of patient visits betore testing } \\
\leqslant 1\end{array}$ & $13(27)$ & $24(73)$ & $<0.0001$ \\
\hline $2-5$ & $14(29)$ & $9(27)$ & NS \\
\hline$\geqslant 6$ & $21(44)$ & $0(0)$ & $<0.00001$ \\
\hline Referred the patient after testing & $41(85)$ & $12(36)$ & $<0.00001$ \\
\hline Concomitant chlamydial screening & $5(10)$ & $9(27)$ & $<0.05$ \\
\hline Concomitant syphilis screening & 7 (15) & $18(55)$ & $<0.001$ \\
\hline Concomitant gonococcal screening & $6(13)$ & $8(24)$ & NS \\
\hline
\end{tabular}

about his/her risk behaviour (84\%); they would notify all sexual partners of STD (other than HIV) patients (69\%) as well as of HIV patients (77\%); they would notify all needle sharing partners (94\%); they wanted the possibility of being able to refer to or co-work with trained counsellors, (89\%); they wanted that the outcome of PN for HIV (84\%), but to a lesser degree for other STD (60\%), should be reported as part of the surveillance; they had discussed safe sex with the index patients (67\%), and they had initiated partner notification (69\%).

Almost all HDs (91\%) had known the index patients less than one month, in contrast to the GPs $(p<0.000001)$. A very low number of patients had therefore visited the HDs before HIV testing, whereas $44 \%$ of the GPs had seen the index patients at least 6 times before the date of HIV testing ( $p<0.0001)$. Most of the GPs (85\%) had referred their patients to a hospital department (table 1). The percentage of index patients from GPs who had also been screened for other STDs, was lower than that from HDs for chlamydial infection $(\mathrm{p}<0.05)$ and syphilis $(\mathrm{p}<0.001)$, but not for gonococcal infection (table 1).

\section{Index patients}

The 102 index patients included 79 male and 23 female patients. Partner notification had been performed in $55(70 \%)$ male patients and $18(78 \%$ ) female patients (table 2$)$. The reported number of partners found relevant to notify was 78 , corresponding to $1 \cdot 1$ partner of each male index patients and 0.8 partner of each female index patient. For $23(32 \%)$ index patients (no gender differences), the index doctors actually said that they were not aware

Table 2 Information about the HIV partner notification process of 55 male and 18 female index patients based on an interview with 81 HIV reporting doctors coming from general practice and different hospitals and clinics in Denmark

\begin{tabular}{llll}
\hline & \multicolumn{3}{l}{ Index patients } \\
\cline { 2 - 5 } \cline { 2 - 4 } & $\begin{array}{l}\text { Male } \\
(n=55)\end{array}$ & $\begin{array}{l}\text { Female } \\
(n=18)\end{array}$ & $\begin{array}{l}\text { Total } \\
(n=73)\end{array}$ \\
\hline Partners relevant to notify & 63 & 15 & 78 \\
Partners reportedly notified by the index doctors & 6 & 1 & 7 \\
Partner reportedly notified by the index patient & 42 & 11 & 53 \\
Reported partners tested HIV positive & 8 & 1 & 9 \\
Reported partners tested HIV negative & 20 & 9 & 29 \\
\hline
\end{tabular}

of any partners whom it was relevant to notify. Of the 78 partners, $7(9 \%)$ were notified by the index doctor, $53(68 \%)$ by the index patient, whereas $18(23 \%)$ were not notified according to the information given by the index doctor. The index doctor reported, but it was seldom verified from a record, that a total of 38 partners had been tested and 9 partners $(24 \%)$ tested HIV positive, corresponding to $12 \%(9 / 78)$ tested HIV positive out of the partners relevant to notify. It was not possible to have detailed information about previous test results for the 9 partners that tested positive.

\section{Discussion}

The Danish National Board of Health has recommended that PN (if possible and relevant) should be discussed and implemented when a patient for the first time is diagnosed as HIV infected. Guidelines and formal training have, however, not been set up.

The main differences between GPs and HDs (tables 1 and 2) in this study seems to reflect that $71 \%$ of the GPs had only once or twice diagnosed HIV infection in one of their patients. The GPs are therefore less experienced in post-test counselling, they had a limited number of post graduate courses concerning HIV/AIDS. These differences seem to explain why a significant higher number of GPs felt that they had not enough knowledge to follow asymptomatic HIV infected patients, and also to explain their higher referral rate (table 1). The GPs' lack of confidence in their ability to do follow-up on asymptomatic HIV positive patients is particularly regrettable given that counselling is a fundamental part of much of the work done in general practice..$^{9} 10$

Attitudes to counselling, discussion about risk behaviour, who is to be notified, and the psychological problems with giving a positive HIV-test result did, however, not differ between the two groups of doctors and were comparable to that found among physicians in a study from the United Kingdom. ${ }^{11}$

Persons requesting an HIV test may not consider themselves at risk of having acquired 
other STDs although this risk is in fact much higher. ${ }^{12}$ Only a minority (10\% of the GPs and $27 \%$ of the HDs) had screened their patients for Chlamydia trachomatis, the most prevalent bacterial STD in Denmark, and screening for other STDs were also exceptional.

The outcome of a PN process based on an interview one year later must be interpreted with caution, as the measurable outcome depends upon what the index doctor might have recorded or was able to recall retrospectively. However, $73 \%$ of the GPs and $64 \%$ of the HDs felt that they had performed PN although it had been problematic in many cases, for example, if the index patient was lost to follow up, referred for further examination, or had had anonymous partners. It was, however, clearly demonstrated that the average number of partners found relevant to notify was very low, only $1 \cdot 1$ for each male and 0.8 for each female index patient.

The notification of the partners, the majority being steady partners, was almost exclusively performed by patient referral that is, by the index patients themselves. It has been shown that provider referral may lead to more partners being notified; ${ }^{8}$ a system where provider referral can be offered and handled by specially educated and trained counsellors should therefore be aimed at. ${ }^{4-68}$ The number of trained counsellors in Denmark is low and geographically concentrated to the three largest cities, although HIV infected cases have been diagnosed in every county in Denmark. It is therefore important that HIV testing doctors are either more prepared for counselling and PN themselves or have the possibility to co-work with or refer to a trained counsellor.

Among the notified partners in this study the index doctors reported that they were aware of the HIV test result in 38 cases, 9 of whom were HIV positive, equalling a minimum of $12 \%$ of the 78 partners who should have been notified. Though information about previous test results for the 9 partners tested
HIV positive was not recorded, it seems reasonable to conclude that the outcome is comparable to that from other studies. ${ }^{458}$ These preliminary results therefore demonstrate that PN for HIV infection does take place in Denmark. The doctors and especially the GPs are, however, most often left alone with this process resulting in the very limited number of PN by provider referral.

The interviewed doctors wanted a registration of the HIV notification outcome. This is only possible in a prospective study with predefined questions that can be registered. Such a registration can, however, only measure the outcome to a certain level in a country like Denmark where exposed named partners are neither obliged to be tested nor counselled, and where the result of a test taken in one healthcare setting can not routinely be reported to another physician.

1 Potterat J, Meheus A, Gallwey J. Partner notification: operational considerations. Int $\mathscr{f} S T D$ AIDS 1991;2: operation.

2 Adler MW, Johnson AM. Contact tracing for HIV infection. $B M \mathcal{F} 1988 ; 296: 1420-1$.

3 Rutherford GW, Woo JM. Contact tracing and the control of human immunodeficiency virus infection. $\mathscr{f} A M A$ 1988;259:3609-10.

4 Giesecke J, Ramstedt K, Granath F, Ripa T, Rådö G, Westrell $M$. Efficacy of partner notification for HIV infection. Lancet 1991;338:1096-9.

5 Wykoff RF, Jones JL, Longshore ST, et al. Notification of the sex and needle-sharing partners of individuals with human immunodeficiency virus in rural South Carolina: 30 month experience. Sex Transm Dis 1991;18:217-21.

6 Pattman RS, Gould EM. Partner notification for HIV infection in the United Kingdom: a look back on seven years experience in Newcastle upon Tyne. Genitourin Med 1993;69:94-7.

7 Pavia AT, Benyo M, Niler L, Risk I. Partner notification for control of HIV: results after 2 years of a statewide program in Utah. Am $\mathcal{F}$ Public Health 1993;83:1418-24.

8 Landis SE, Schoenbach VJ, Weber DJ, et al. Results of a randomized trial of partner notification in cases of HIV infection in North Carolina. N Engl f Med 1992;326: 101-5.

9 Brown-Peterside P, Sibbald B, Freeling P. AIDS: knowledge, skills and attitudes among vocational trainees and edge, skills and attitudes among vocational
their trainers. Br $\mathcal{F}$ Gen Pract 1991;41:401-5.

their trainers. Brf Gen Pract $1991 ; 41: 401-5$.
10 Milne R, Keen SM. Are general practitioners ready to prevent the spread of HIV? $B M \Im$ $1988 ; 296: 533-5$.

11 Keenlyside RA, Hawkins AS, Johnson AM, Adler MW. Attitudes to tracing and notifying contacts of people with HIV infection. $B M \Im$ 1992;305:165-8.

12 Mohanty KC. Sexually transmitted diseases among patients seeking HIV antibody test for AIDS. Int $\mathcal{F} S T D$ AIDS 1990;1:207-8. 